\title{
Effect of Aspartic Acid Family Amino Acids on Production of Maridomycin III*
}

\author{
Ken-ichiro Miyagawa, Masaru Suzuki, Eiji Higashide \\ and Minoru UCHIDA \\ Microbiological Research Laboratories, Central Research Division, \\ Takeda Chemical Industries, Lid., Osaka, Japan
}

Received January 16,1979

\begin{abstract}
An attempt was made to increase the production of maridomycin III (MDM III) as the major component among the six components of maridomycin (maridomycin I, II, III, IV, V and VI). Addition to the production medium, of amino acids belonging to the aspartic acid family and its related compounds, such as L-isoleucine, L-threonine, L-methionine, L-homoserine, DL- $\alpha$-amino- $n$-butyric acid and $\alpha$-ketobutyric acid, resulted in a yield of a large amount of MDM III.

MDM III was also formed by intact cells from 4"-depropionyl MDM III and the same compounds. From 4 "'-depropionyl MDM III and L-isoleucine-U ${ }^{14} \mathrm{C}$ (or DL- $\alpha$-amino- $n$ butyric acid-3-14 $\mathrm{C}$, MDM III- ${ }^{14} \mathrm{C}$ was formed, and a large amount of radioactivity was incorporated into MDM III. On deacylation at $\mathrm{C}-4$ " of the MDM III- ${ }^{14} \mathrm{C}$, about $90 \%$ of radioactivity of MDM III-14 $\mathrm{C}$ was observed as propionic acid- ${ }^{14} \mathrm{C}$.

In the same way, SF-837. ${ }^{14} \mathrm{C}$ was formed from leucomycin $\mathrm{A}_{T}$ and $\mathrm{L}$-isoleucine-U. ${ }^{14} \mathrm{C}$ (or DL- $\alpha$-amino-n-butyric acid- $-3-{ }^{14} \mathrm{C}$ ), and deacylation of the SF-837-14 $\mathrm{C}$ at $\mathrm{C}-3$ also gave propionic acid $-{ }^{14} \mathrm{C}$. From these results, $L$-isoleucine and $\mathrm{DL}-\alpha$-amino- $n$-butyric acid were considered to be precursors of the propionyl groups at $\mathrm{C}-3$ and $\mathrm{C}-4$ " of 16-membered macrolide antibiotics.
\end{abstract}

Many organisms producing 16-membered macrolide antibiotics accumulated closely related antibiotics with different acyl groups at $\mathrm{C}-3$ and $\mathrm{C}-4^{\prime \prime}$. For example, leucomycin is composed of eight components that are different from each other only in the acyl groups. ${ }^{1 \sim 3)}$ This is also true of other macrolide antibiotics, such as spiramycin, ${ }^{4}$ ) platenomycin (YL-704 antibiotics), ${ }^{5,0}$ midecamycin (SF-837 antibiotics) ${ }^{7,8}$ etc.

In the course of studies on the microbial production of maridomycin (MDM), it was found that Streptomyces hygroscopicus No. B-5050 produced maridomycin as a mixture of six components (MDM I MDM VI) that differ only in the acyl groups at $\mathrm{C}-3$ and $\mathrm{C}-4$ "' as illustrated in Fig. 1.,20) Among these six components, MDM III was needed for the raw

* Studies on Maridomycin Fermentation. Part II. Presented at the Annual Meeting of the Agricultural Chemical Society of Japan, held in Sapporo, July 25, 1975, and in Kyoto, April 1, 1976.

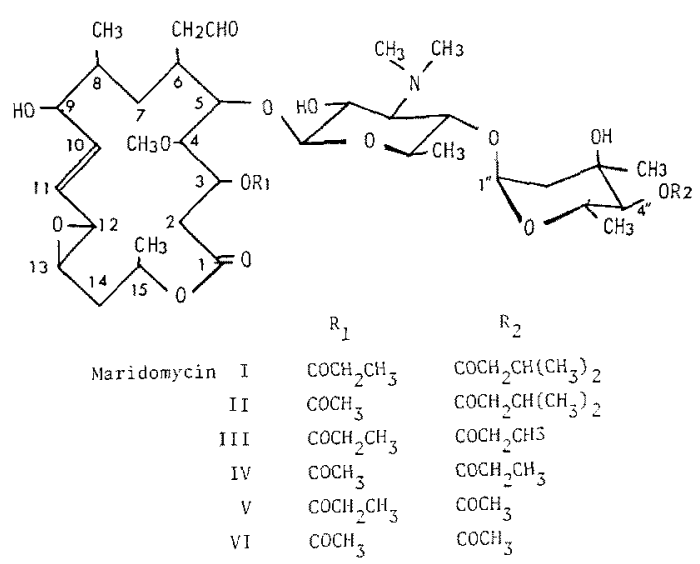

FIG, 1. Structures of Maridomycins.

material of 9-propionyl MDM III, which showed strong chemotherapeutic effects. ${ }^{11)}$ Isolation of MDM III from a mixture of MDM in the culture broth is a time-consuming process because of their similar chemical properties of the six components. If it were possible to produce MDM III as a major component in 
the fermentation, a less expensive isolation process might be available. Many attempts have been made to produce the 16 -membered macrolide antibiotics, but little is yet known about the production of a single component of them. ${ }^{12)}$ The purposes of the present investigation were to clarify the origin of propionyl moieties of MDM III and to direct the biosynthesis of MDM to that of MDM III in the fermentation.

\section{MATERIALS AND METHODS}

Microorganism. Streptomyces hygroscopicus No.B5050-HA, a mutant producing high yield of MDM derived from S. hygroscopicus No. B-5050, ${ }^{13)}$ was used in this study.

\section{Table I. EFfect of Various Compounds ON MDM III Production}

Each compound was added at the concentration of $0.1 \%$ at $24 \mathrm{hr}$ except amino acids, which were added at the concentration of $0.2 \%$ at initial time.

\begin{tabular}{|c|c|c|c|}
\hline Compound & $\frac{\mathrm{MDM}}{(\mu \mathrm{g} / \mathrm{ml})}$ & $\underset{(\mu \mathrm{g} / \mathrm{ml})}{\operatorname{MDM}}$ & $\begin{array}{c}\text { MDM III } \\
/ \%) \\
(\mathrm{MDM}\end{array}$ \\
\hline Acetate & 4300 & 1630 & 38 \\
\hline Propionate & 4250 & 1830 & 43 \\
\hline$n$-Butyrate & 4250 & 1910 & 45 \\
\hline$n$-Valerate & 4000 & 2120 & 53 \\
\hline$n$-Caproate & 3900 & 1560 & 40 \\
\hline Ethyl alcohol & 4350 & 1740 & 40 \\
\hline n-Propyl alcohol & 4250 & 1620 & 38 \\
\hline$n$-Butyl alcohol & 4150 & 1580 & 38 \\
\hline n-Amyl alcohol & 4000 & 1600 & 40 \\
\hline Propionamide & 4350 & 1960 & 45 \\
\hline Succinate & 4600 & 2070 & 45 \\
\hline$\alpha$-Ketoglutarate & 4280 & 1630 & 38 \\
\hline Citrate & 4300 & 1720 & 40 \\
\hline Glutamate & 4450 & 1780 & 40 \\
\hline Glycine & 4380 & 1660 & 38 \\
\hline Arginine & 4450 & 1780 & 40 \\
\hline Aspartate & 4300 & 1940 & 45 \\
\hline Lysine & 4300 & 1720 & 40 \\
\hline Homoserine & 4000 & 2800 & 70 \\
\hline Threonine & 4300 & 3010 & 70 \\
\hline Methionine & 4600 & 3220 & 70 \\
\hline Isoleucine & 4450 & 3340 & 75 \\
\hline$\alpha$-Amino- $n$-butyrate & 3750 & 3000 & 80 \\
\hline$\alpha$-Ketobutyrate & 3680 & 2940 & 80 \\
\hline Leucine & 4400 & $1320^{\circ}$ & 30 \\
\hline None & 4500 & 1800 & 40 \\
\hline
\end{tabular}

a Increase of MDM I and MDM II was observed.
Media. The following media were used for cultivation of microorganism: SB medium contained $10 \mathrm{~g}$ of soluble starch, $0.4 \mathrm{~g}$ of peptone, $0.2 \mathrm{~g}$ of meat extract, $0.2 \mathrm{~g}$ of yeast extract, $0.2 \mathrm{~g}$ of $\mathrm{NZ}$-amine (type $\mathrm{A}$ ) and $20 \mathrm{~g}$ of agar per liter ( $\mathrm{pH} 7.0) ; \mathrm{N}-9$ medium contained $30 \mathrm{~g}$ of glucose, $30 \mathrm{~g}$ of corn steep liquor, $0.5 \mathrm{~g}$ of $\mathrm{MgSO}_{4} \cdot 7 \mathrm{H}_{2} \mathrm{O}$ and $3 \mathrm{~g}$ of $\mathrm{CaCO}_{8}$ per liter ( $\mathrm{pH} 6.5$ ); G-10 medium contained $120 \mathrm{~g}$ of glucose, $20 \mathrm{~g}$ of Profio (Traders Protein Division, U.S.A.), $5 \mathrm{~g}$ of soy bean meal, $5 \mathrm{~g}$ of $\mathrm{NH}_{4} \mathrm{Cl}, 1.2 \mathrm{~g}$ of $\mathrm{KH}_{2} \mathrm{PO}_{4}, 0.5 \mathrm{~g}$ of $\mathrm{MnSO}_{4}$. $4-6 \mathrm{H}_{2} \mathrm{O}, 0.2 \mathrm{~g}$ of $\mathrm{MgSO}_{4} \cdot 7 \mathrm{H}_{2} \mathrm{O}, 1.0 \mathrm{~g}$ of $\mathrm{FeSO}_{4} \cdot 7 \mathrm{H}_{2} \mathrm{O}$, $0.5 \mathrm{~g}$ of $\mathrm{ZnSO}_{4} \cdot 7 \mathrm{H}_{2} \mathrm{O}$ and $12 \mathrm{~g}$ of $\mathrm{CaCO}_{3}$ per liter (pH 6.5); $\mathrm{S}-1$ medium contained $50 \mathrm{~g}$ of glucose, $10 \mathrm{~g}$ of meat extract, $10 \mathrm{~g}$ of peptone, $5 \mathrm{~g}$ of $\mathrm{NaCl}$ and $5 \mathrm{~g}$ of $\mathrm{CaCO}_{3}$ per liter ( $\left.\mathrm{pH} 6.5\right)$.

Culture conditions. The spores grown on SB agar slant at $28^{\circ} \mathrm{C}$ for 7 days were suspended in $5 \mathrm{ml}$ of sterile water. Half a milliliter of the suspension thus obtained was used to inoculate $200-\mathrm{ml}$ Erlenmeyer flasks containing $20 \mathrm{ml}$ of $\mathrm{N}-9$ medium. Incubation was carried out at $28^{\circ} \mathrm{C}$ for $48 \mathrm{hr}$ on a rotary shaker. One milliliter of the culture broth was transferred into $20 \mathrm{ml}$ of $\mathrm{G}-10$ medium in a $200-\mathrm{ml}$ Erlenmeyer flask. Incubation was continued for 6 days at $26^{\circ} \mathrm{C}$ on the rotary shaker to attain the maximal production of MDM.

Preparation of washed cells. One milliliter of the culture broth (N-9) was transferred into $20 \mathrm{ml}$ of S-1 medium in a $200-\mathrm{ml}$ Erlenmeyer flask and incubation was carried out for $24 \mathrm{hr}$ at $28^{\circ} \mathrm{C}$. The cells were harvested by centrifugation at $2500 \times g$ for $10 \mathrm{~min}$ below $5^{\circ} \mathrm{C}$ and were washed twice with sterile water and then were made up to $16 \mathrm{ml}$ of cell suspension with $0.2 \mathrm{M}$ potassium phosphate buffer ( $\mathrm{pH} 6.0$ ).

Analytical methods. MDM was measured colorimetrically according to the method described in a previous paper. ${ }^{14)}$ Quantitative analysis of six components of MDM was carried out with high speed liquid chromatography.15) Cell weight was determined by measuring protein content after sonication of the cells. ${ }^{18)}$

Measurement of radioactivity. Liquid scintillation counter (Aloka L.S.C. 502, Nihon Musen Co., Tokyo) was used for the measurement of radioactivity. The scintillater was consisted of $1000 \mathrm{~g}$ of naphthalene, $120 \mathrm{~g}$ of PPO, $3 \mathrm{~g}$ of POPOP, 7.2 liters of dioxane, 1.35 liters of toluene and 0.45 liter of methanol. A thinlayer chromatography-scanner (Aloka TRM-1B) was used for the detection of radioactivity.

Chemicals. 4"-Depropionyl MDM III was prepared from MDM III by the method of Nakahama et al. ${ }^{17}$ Leucomycin $A_{7}$ was purified from commercial preparations according to the procedure of Suzuki et al. ${ }^{18)}$ DL-a-Amino- $n$-butyric acid-3 ${ }^{14} \mathrm{C}$ and $\mathrm{L}$ - 
isoleucine- $\mathrm{U}^{14} \mathrm{C}$ were obtained from Service des Molecules Morqueés, France and Daiichi Kagaku Co., Tokyo, respectively. TLC plate was purchased from Tokyo Kasei Co., Tokyo.

\section{RESULTS}

Effect of several compounds on MDM III production

Several compounds that appear to be structurally related to the acyl groups at $\mathrm{C}-3$ and C- 4 " of MDM III were tested for their effect on MDM III production by adding these compounds to the culture. The results are summarized in Table I. Compounds such as the lower fatty acids, lower alcohols and propionamide had no effect on MDM III production. Organic acids belonging to TCA cycle members also had no effect. Addition of amino acid belonging to aspartic acid family and its related compound, such as L-isoleucine (Ile), L-threonine, L-methionine, L-homoserine, DL$\alpha$-amino- $n$-butyric acid $(\alpha-A B)$ and $\alpha$-ketobutyric acid $(\alpha-K B)$ yielded MDM III as a major component. Among these compounds, Ile was found to be a favorable compound for MDM III production. Addition of $\alpha$ $\mathrm{AB}$ or $\alpha-\mathrm{KB}$, which has an inhibitory effect on the growth, resulted in a poor yield of MDM compared with the control culture. On the other hand, addition of L-leucine yielded a large amount of MDM I and MDM II without changing productivity of MDM compared with the control culture. This observation is in good agreement with the biogenetic study by Grisebach and Auchenbach that indicated Lleucine was an efficient precursor of the isovaleryl unit at C -4 " of carbomycin. ${ }^{19}$

\section{Formation of MDM III from 4"-depropionyl MDM III by intact cells}

A number of compounds were investigated for their effect on the formation of MDM III from 4 "'-depropionyl MDM III by intact cells. As shown in Table II, amino acids belonging to the aspartic acid family and its related compound had a considerable effect on the formation of MDM III from 4"'-depropionyl MDM III. Other amino acids, some organic acids,
TABle II. EFFECT OF Various Compounds ON Formation of MDM III From 4"-DepropionyL MDM III BY INTACT CELLS

The reaction mixture contained $50 \mathrm{mg}$ of washed cells (as dry weight), $1.0 \mathrm{mmol}$ of potassium phosphate buffer (pH 6.0), $5.0 \mu \mathrm{mol}$ of $4^{\prime \prime}$-depropionyl MDM III and $50 \mu \mathrm{mol}$ of compound in a total volume of $5 \mathrm{ml}$ and were incubated for $1 \mathrm{hr}$ at $28^{\circ} \mathrm{C}$.

\begin{tabular}{|c|c|c|}
\hline Compound & $\begin{array}{l}\text { MDM III formed } \\
(\mathrm{nmol} / \mathrm{ml})\end{array}$ & $\begin{array}{c}\text { Conversion } \\
\text { rate }^{\alpha}\end{array}$ \\
\hline Acetate & 70 & 7 \\
\hline Propionate & 90 & 9 \\
\hline n-Butyrate & 80 & 8 \\
\hline$n$-Valerate & 100 & 10 \\
\hline n-Caproate & 60 & 6 \\
\hline Ethyl alcohol & 70 & 7 \\
\hline n-Propyl alcohol & 90 & 9 \\
\hline n-Butyl alcohol & 80 & 8 \\
\hline n-Amyl alcohol & 60 & 6 \\
\hline Propionamide & 90 & 9 \\
\hline Succinate & 80 & 8 \\
\hline$\alpha$-Ketoglutarate & 90 & 9 \\
\hline Citrate & 60 & 6 \\
\hline Gutamate & 60 & 6 \\
\hline Glycine & 70 & 7 \\
\hline Arginine & 60 & 6 \\
\hline Aspartate & 80 & 8 \\
\hline Lysine & 60 & 6 \\
\hline Homoserine & 400 & 40 \\
\hline Threonine & 350 & 35 \\
\hline Methionine & 250 & 25 \\
\hline Isoleucine & 400 & 40 \\
\hline$a$-Amino- $n$-butyrate & 450 & 45 \\
\hline a-Ketobutyrate & 450 & 45 \\
\hline Leucine & $60^{b}$ & 6 \\
\hline None & 70 & 7 \\
\hline
\end{tabular}

a Expressed as relative value, taking 4"-depropionyl MDM III added to the reaction mixture as $100(\%)$

$b$ Increase of MDM I was observed.

lower alcohols and lower fatty acids had no effect on the acylation of $4^{\prime \prime}$-depropionyl MDM III. These results correlated with those obtained in the fermentation experiments and suggested that MDM producing-organism had an enzyme system forming MDM III from 4 "'-depropionyl MDM III plus degradation products of amino acids as an acyl donor.

To ascertain that $\alpha-\mathrm{AB}$ or Ile was a precursor of the propionyl group at $\mathrm{C}-4$ " of MDM III, the formation of MDM $I I{ }^{14} \mathrm{C}$ from $4^{\prime \prime}$-depropionyl MDM III plus $\alpha-A B-{ }^{14} \mathrm{C}$ 


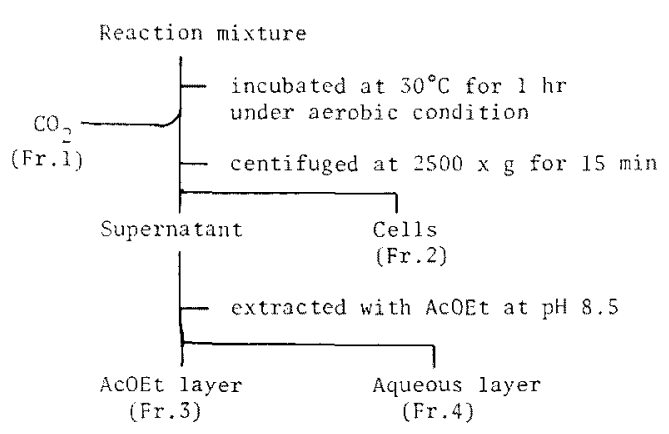

Fig. 2. Procedure for Formation and Isolation of MDM III- ${ }^{14} \mathrm{C}$ from 4 "'-Depropionyl MDM III,

The reaction mixture consisted of $5.0 \mu \mathrm{mol}$ of $4^{\prime \prime}-$ depropionyl MDM III, $5.0 \mu \mathrm{mol}$ of DL- $\alpha$-amino- $n$ butyric acid [specific activity of $8.4 \times 10^{5}$ counts $/ \mathrm{min}$. $\mu \mathrm{moll}, 0.8 \mathrm{mmol}$ of potassium phosphate buffer ( $\mathrm{pH} \mathrm{6.0)}$ and $40 \mathrm{mg}$ of washed cells (as dry weight) in a total volume of $4.0 \mathrm{ml}$.

was studied by intact cells. The procedure of the formation and the isolation of MDM III- ${ }^{14} \mathrm{C}$ is illustrated in Fig. 2. The radioactive substance in ethyl acetate solution was identified as MDM III- ${ }^{14} \mathrm{C}$ by means of thinlayer chromatography-scanner (Fig. 3). The radioactive MDM III was also obtained by using Ile- ${ }^{14} \mathrm{C}$ instead of $a-A B-{ }^{14} \mathrm{C}$ in the same way. Distribution of radioactivity in the reaction products in the process for the formation and isolation of MDM III $-{ }^{14} \mathrm{C}$ is summarized in Table III. As is obvious from Table III, $48 \%$ of the radioactivity of added $\alpha-\mathrm{AB}$ and $31 \%$ of that of Ile were incorporated into MDM III.

\section{Deacylation of $M D M I I I-{ }^{14} C$}

The MDM III- ${ }^{14} \mathrm{C}$ obtained was deacylated

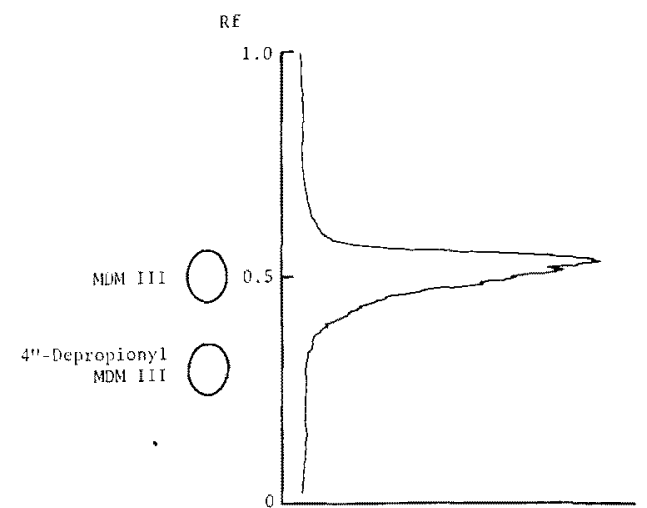

FIG. 3. Thin-layer Chromatogram Illustrating MDM III-14 C formed from 4"-Depropionyl MDM III. Ethyl acetate layer (Fr. 4 in Fig. 2) was concentrated in vacuo to a small volume and spotted on thin-layer chromatographic plate (silica gel). Radioactivity was detected by TLC-scanner after development with the upper layer of ethyl ether $-i$-propanol- $n$-hexane-water $(4: 1: 1: 2)$.

at $\mathrm{C}-4^{\prime \prime}$ to confirm that the radioactivity localized in the propionyl group at $\mathrm{C}-4^{\prime \prime}$ of MDM III- ${ }^{14} \mathrm{C}$. MDM III- ${ }^{14} \mathrm{C}$ was extracted with methanol from an appropriate area of thin-layer chromatographic plate, and was concentrated to dryness in vacuo. This residue was taken into aqueous solution with succinic acid and used for the substrate of the following reaction. Enzymatic deacylation at $\mathrm{C}-4$ "' of MDM III- ${ }^{14} \mathrm{C}$ was carried out by the method of Nakahama et al. ${ }^{17}$ (Fig. 4), and a large part of radioactivity ( $89 \%$ of radioactivity in MDM III- ${ }^{14} \mathrm{C}$ ) was extracted into ethyl ether fraction (Fr. 3 of Table IV). The radioactive substance in ethyl ether fraction was identified as propionic acid- ${ }^{14} \mathrm{C}$ as shown

Table III. Distribution of Radioactivity IN the Procedure for

Formation AND IsOLATION OF MDM III $-{ }^{14} \mathrm{C}$ AND SF-837-14 C

\begin{tabular}{|c|c|c|c|c|c|}
\hline \multicolumn{2}{|c|}{ Substrate } & \multicolumn{4}{|c|}{ Radioactivity } \\
\hline \multirow[t]{2}{*}{ Antibiotics } & \multirow{2}{*}{$\begin{array}{l}{ }^{14} \mathrm{C}- \\
\text { Compound }\end{array}$} & $\mathrm{CO}_{2}$ & Cell & AcOEt layer & Aqueous layer \\
\hline & & $(\%)^{a}$ & $(\%)^{a}$ & $\operatorname{dpm}(\%)^{a}$ & $\mathrm{dpm}$ \\
\hline \multirow{2}{*}{$\begin{array}{c}4^{\prime \prime}-\text { Depropionyl } \\
\text { MDM III }\end{array}$} & 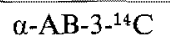 & $5(5.2)$ & $5^{5}(8.3)$ & $2.02 \times 10^{8}(48.0)$ & $1.62 \times 10^{8}(38.5)$ \\
\hline & Ile-U- ${ }^{14} \mathrm{C}$ & $0^{5}(21.7)$ & ${ }^{5}(19.0)$ & $0^{5}(31.0) \quad 7$ & 8.3) \\
\hline \multirow[t]{2}{*}{ Leucomycin $A_{7}$} & ${ }^{14} \mathrm{C}$ & ${ }^{5}(4.1)$ & $5(5.6)$ & $2.31 \times 10^{\circ}(55.0)$ & $1.48 x$ \\
\hline & Ile-U $-{ }^{14} \mathrm{C}$ & $5.47 \times 10^{5}(20.8)$ & $3.60 \times 10^{5}(13.7)$ & $8.42 \times 10^{5}(32,0) \quad 8$ & $8.81 \times 10^{5}(33.5)$ \\
\hline
\end{tabular}

a Expressed as relative value, taking the radioactivity of ${ }^{14} \mathrm{C}$-compound added to the reaction mixture as $100(\%)$.

Abbreviations: $\alpha$-AB,DL- $\alpha$-amino- $n$-butyric acid; Ile, L-isoleucine. 


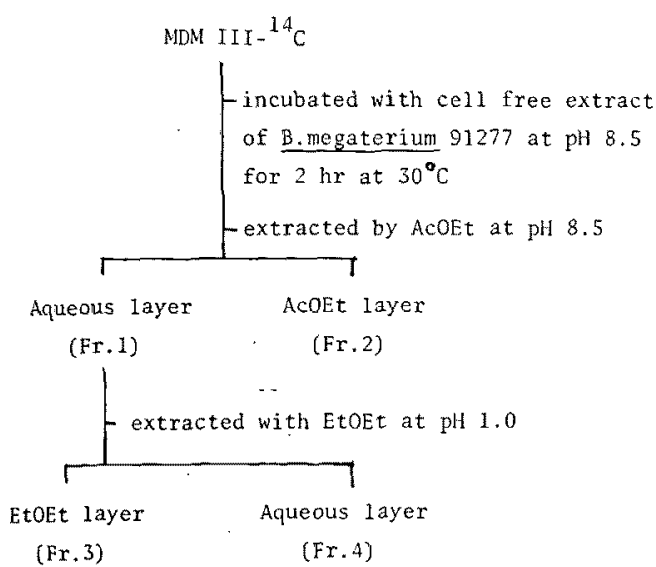

Frg. 4. Procedure for Deacylation of MDM $M \mathrm{II}^{-14} \mathrm{C}$.

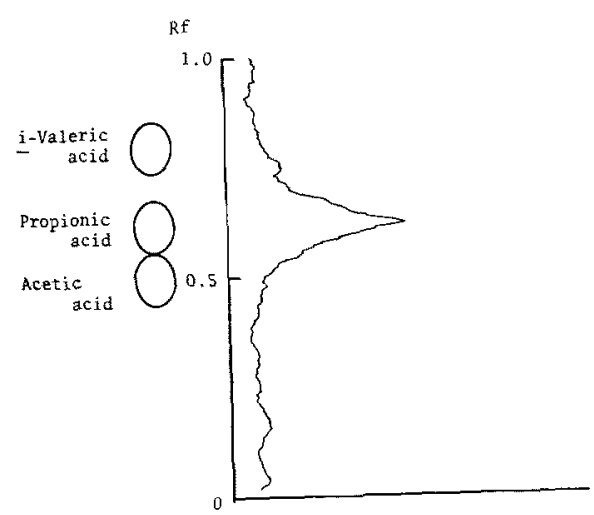

Frg. 5. Thin-layer Chromatogram Illustrating the Deacylation Product of MDM III- ${ }^{1+} \mathrm{C}$.

Ethyl ether layer (Fr. 3 in Fig. 4) was concentrated in vacuo after addition of $\mathrm{NH}_{4} \mathrm{OH}$ water, and spotted on TLC plate (cellulose). Radioactivity was detected by TLC-scanner after development of it with $n$-propanol-conc. $\mathrm{NH}_{4} \mathrm{OH}$ water-water $(9: 2: 1)$.

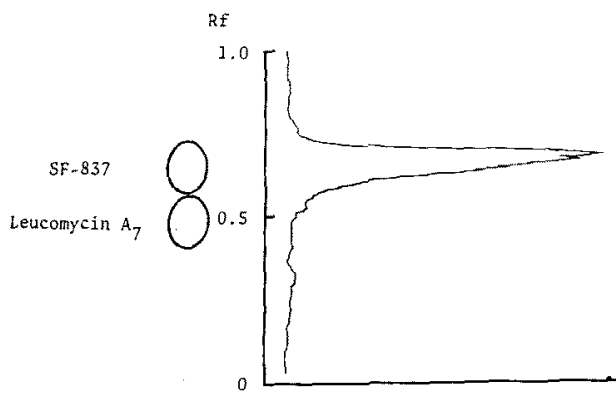

FIG. 6. Thin-layer Chromatogram Illustrating SF$837-{ }^{14} \mathrm{C}$ formed from Leucomycin $\mathrm{A}_{7}$.

Detection of radioactivity was carried out as described in Fig. 3.
Table IV. Distribution of Radioactivity in Deacylation Products of MDM III- ${ }^{14} \mathrm{C}$

\begin{tabular}{llr}
\hline Fractions $^{a}$ & $\begin{array}{c}\text { Radioactivity } \\
(\mathrm{dpm})\end{array}$ & $(\%)^{b}$ \\
\hline Fr. 1 Aqueous layer & $1.02 \times 10^{5}$ & 93.0 \\
Fr. 2 Ethyl acetate layer & $7.70 \times 10^{3}$ & 7.0 \\
Fr. 3 Ethyl ether layer & $9.79 \times 10^{4}$ & 89.0 \\
Fr. 4 Aqueous layer & $4.07 \times 10^{3}$ & 3.7 \\
\hline a Fraction number in this table corresponds with \\
that of Fig. 4. \\
Expressed as relative value, taking the radio- \\
activity of added MDM III as $100(\%)$.
\end{tabular}

in Fig. 5. From these results, the propionyl unit at C-4" of MDM III was proved to be derived from $\alpha-\mathrm{AB}$ or Ile.

\section{Formation of radioactive $S F-837$ from leucom- ycin $\mathrm{A}_{\bar{T}}$}

As shown in Fig. 1, MDM III has two propionyl groups, one at $\mathrm{C}-4^{\prime \prime}$ and the other at $\mathrm{C}-3$ of lactone ring. So, it is probable that $\alpha-\mathrm{AB}$ or Ile is also a precursor of the propionyl group at $\mathrm{C}-3$ of MDM III. To examine this probability, the formation of SF$837-{ }^{14} \mathrm{C}$ from leucomycin $\mathrm{A}_{7}$ plus $\alpha-\mathrm{AB}^{-14} \mathrm{C}$ was investigated by intact cells. Leucomycin $\mathrm{A}_{7}$ has the same structure as MDM III except for the structure of $\mathrm{C}-3$ and $\mathrm{C}-12 \sim \mathrm{C}-13$ of the lactone ring. It has a hydroxyl group at $\mathrm{C}-3$ of lactone ring. ${ }^{2}$ Therefore, it seems to be a favorable compound for studying the acylation at $\mathrm{C}-3$. The procedure for the formation and isolation of the $\mathrm{SF}-837-{ }^{14} \mathrm{C}$ was the same as shown in Fig. 2, except that leucomycin $A_{7}$ was used as substrate of the reaction instead of 4 "'-depropionyl MDM III. Distribution of radioactivity in the process for formation and isolation of $\mathrm{SF}-837-{ }^{-4} \mathrm{C}$ is summarized in Table III. As is obvious from Fig. 6 , the radioactive substance in ethyl acetate layer was proved to be $\mathrm{SF}-837-{ }^{14} \mathrm{C}$. Furumai et al., reported that the acylation at $\mathrm{C}-3$ was observed in early step of biosynthesis of platenomycin. ${ }^{203}$ So, it is possible to consider that there are at least two types of acylation at $\mathrm{C}-3$ of $16-$ membered macrolide antibiotics.

Deacylation of $S F-837-{ }^{14} \mathrm{C}$

Two step-deacylation processes were em- 


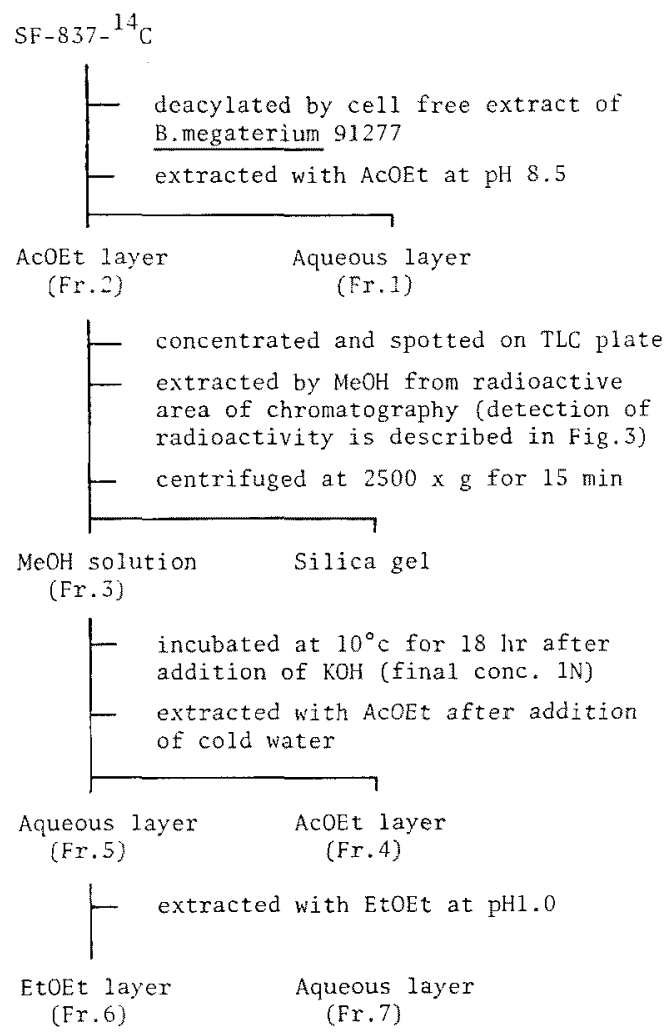

Fig. 7. Procedure for Deacylation on $\mathrm{SF}-837 \cdot{ }^{14} \mathrm{C}$.

ployed for the deacylation of $\mathrm{SF}-837-{ }^{14} \mathrm{C}$ as illustrated in Fig. 7. First, deacylation at $\mathrm{C}-4$ " of SF-837 was carried out by using cell free extract of $B$. megaterium 91277. ${ }^{17}$ ) After enzymatic deacylation, the reaction mixture was extracted with ethyl acetate. The major part of radioactivity was transferred into ethyl acetate layer (Table V). As shown in Fig. 8,

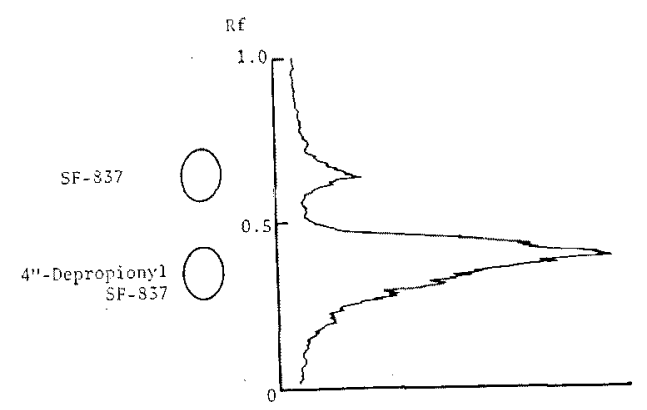

FIG. 8. Thin-layer Chromatogram Illustrating the Deacylation Product of SF-837-14C.

Radioactivity of ethyl acetate layer (Fr. 2 in Fig. 7) was detected in the same manner as described in Fig. 3.

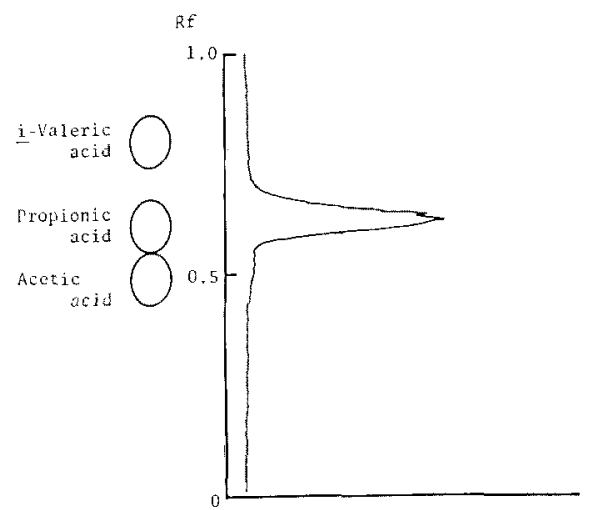

Fig. 9. Thin-layer Chromatogram Illustrating the Deacylation Product of 4 "-Depropionyl SF-837-14C. Radioactivity of ethyl ether layer (Fr. 6 in Fig. 7) was detected in the same manner as described in Fig. 5.

Table V. Distribution of Radioactivity in Deacylation Products of SF-837- ${ }^{14} \mathrm{C}$

\begin{tabular}{llc}
\hline Fractions & \multicolumn{2}{c}{ Radioactivity } \\
& \multicolumn{1}{c}{$(\mathrm{dpm})$} & $\left.{ }^{b}\right)^{b}$ \\
\hline Fr. 1 Aqueous layer & $1.77 \times 10^{5}$ & 13.6 \\
Fr. 2 Ethyl acetate layer & $1.12 \times 10^{6}$ & 86.4 \\
Fr. 3 Methanol solution & $8.98 \times 10^{5}$ & 69.1 \\
$\quad$ (4"'-Depropionyl SF-837) & & \\
Fr. 4 Ethyl acetate layer & $4.55 \times 10^{4}$ & 3.5 \\
Fr. 5 Aqueous layer & $8.53 \times 10^{5}$ & 65.6 \\
Fr. 6 Ethyl ether layer & $8.19 \times 10^{5}$ & 63.0 \\
Fr. 7 Aqueous layer & $3.38 \times 10^{4}$ & 2.6 \\
\hline
\end{tabular}

a Fraction number in this table corresponds with that of Fig. 7.

$b$ Expressed as relative value, taking the radioactivity of added SF-837-14 $\mathrm{C}$ as $100(\%)$.

ethyl acetate fraction contained two radioactive substance, residual SF-837. ${ }^{14} \mathrm{C}$ and $4^{\prime \prime}$ depropionyl SF-837- ${ }^{14} \mathrm{C}$. $\quad 4^{\prime \prime}$-Depropionyl SF $-837-{ }^{14} \mathrm{C}$ was obtained by extraction with methanol from chromatographic plate, and was used as the substrate of the second deacylation reaction. Then 4"'-depropionyl SF-837${ }^{14} \mathrm{C}$ was deacylated at $\mathrm{C}-3$ by the method of Muroi et al. ${ }^{21)}$ The reaction product was extracted with ethyl ether and the radioactive substance was identified as propionic acid (Fig. 9). More than $90 \%$ of the radioactivity of $4{ }^{\prime \prime}$-depropionyl $\mathrm{SF}-837-{ }^{14} \mathrm{C}$ was obtained as propionic acid- ${ }^{14} \mathrm{C}$ (Fr. 6 of Table V). Thus, the propionyl group at $\mathrm{C}-3$ of lactone ring was found to be derived from $\alpha-\mathrm{AB}$ or Ile. 


\section{DISCUSSION}

In our studies on MDM production, attempts were made to improve the production of MDM III, by general procedures employed in the improvement of antibitics productivity, such as mutation and selection of strains, composition of media and culture conditions. But, in most cases, the production of MDM III was accompanied by the increase of the other five components (MDM I, II, IV, V, VI). As described in "REsults," it was found that addition of some amino acids to the medium gave the desired increase in the production of MDM III, accompanied by a decrease of the production of other five components. In our experiments on intact cells, these amino acids were proved to be precursors of the propionyl moieties at $\mathrm{C}-4^{\prime \prime}$ and $\mathrm{C}-3$ of the macrolides. We also found that MDM III was formed from $4^{\prime \prime}$-depropionyl MDM III plus propionyl CoA and that MDM $V$ was formed from 4 "'-depropionyl MDM III plus acetyl CoA by using cell free extract of the same strain. ${ }^{22}$ Amino acids belonging to the aspartic acid family are known to be degraded to propionyl $\mathrm{CoA}$, and L-leucine, the addition of which yielded increased MDM I and II, is known to be degraded to isovaleryl CoA. The following speculation is suggested as an explanation for these observations: higher level of exogenous amino acids may direct the biosynthesis of MDM to the production of one component whose acyl group is derived from the degradation product of those amino acids.

We are much interested in the enzyme which catalyzes the acylation at $\mathrm{C}-3$ and $\mathrm{C}-4$ " of MDM, and also interested in the relation between the biosynthesis of amino acids and that of MDM. Studies on the enzymes of acylation and on mutants with regulatory properties for the aspartic acid family amino acids are in progress. Results will be published in the near future.
Acknowledgment. The authors wish to thank Drs. M. Isono, M. Asai, T. Kishi and T. Kanamaru for their helpful advices and encouragement throughout this study. Thanks are also due to Mr. Himeno for his skillful assistance.

\section{REFERENCES}

1) S. Ömura, M. Katagiri and T. Hata, J. Antibiot., 21, 199 (1968).

2) S. Omura, M. Katagiri and T. Hata, ibid., 21, 272 (1968).

3) S. Ōmura, A. Nakagawa, M. Katagiri, T. Hata, M. Hiramatsu, T. Kimura and K. Naya, Chem. Pharm. Bull., 18, 1501 (1970).

4) R. B. Woodwatd, L. S. Weiler and P. C. Dutta, J. Am. Chem. Soc., 87, 4660 (1965).

5) A. Kinumaki, I. Takamori, Y. Sugawara, M. Suzuki and T. Okuda, J. Antibiot., 27, 107 (1974).

6) A. Kinumaki, I. Takamori, Y. Sugawara, Y. Seki, M. Suzuki and T. Okuda, ibid., 27, 117 (1974).

7) S. Inouye, T. Tsuruoka, S. Omoto and T. Niida, ibid., 24, 460 (1971).

8) T. Tsuruoka, S. Inouye, T. Shomura, N. Ezaki and T. Niida, ibid., 24, 526 (1972).

9) M. Muroi, M. Izawa, H. Ono, E. Higashide and T. Kishi, Experientia, 28, 878 (1972).

10) M. Muroi, M. Izawa and T. Kishi, ibid., 28, 129 (1972).

11) S. Harada, M. Muroi, M. Kondo, K. Tsuchiya, T. Matsuzawa, T. Fugono, T. Kishi and J. Ueyanagi, Antimicro. Agents. Chemoth., 4, 140 (1973).

12) L. Ninet and J. Verrier, Fr. Patent No. 1262571 (1958).

13) H. Ono, T. Hasegawa, E. Higashide and $M$. Shibata, J. Anlibiot, 26, 191 (1973).

14) M. Uchida, M. Suzuki, T. Takayama and N. Sugita, Agric. Biol. Chem., 43, 847 (1979).

15) K. Kondo, J. Chromatogr., 169, 329 (1979).

16) H. Sawada, M. Suzuki and M. Uchida, J. Ferment. Technol., in press.

17) K. Nakahama, M. Izawa, M. Muroi, T. Kishi, M. Uchida and S. Igarashi, J. Antibiot., 27, 425 (1974).

18) T. Suzuki, M. Asai and N. Sugita, Japan Patent applied, Tokukaisho 48-76880, laid open (1973).

19) H. Grisebach und H. Auchenbach, Experientia, 19, 6 (1963).

20) T. Furumai, K.Takeda and M.Suzuki, J.Antibiot., 28, 789 (1975).

21) M. Muroi, M. Izawa and T. Kishi, Chem. Pharm. Bull., 24, 463 (1976).

22) M. Uchida, M. Suzuki, K. Miyagawa, N. Sugita, H. Sawada and E. Higashide, Abstracts of papers, Annual Meeting of the Agricultural Chemical Society of Japan, Sapporo, July, 1975, p. 86. 